\title{
Matrix Metalloproteinase-9 -1562T Allele and its Combination with MMP-2 -735 C Allele are Risk Factors for Breast Cancer
}

\author{
Zohreh Rahimi $^{1,2 *}$, Kheirolah Yari ${ }^{1}$, Ziba Rahimi $^{1}$
}

\begin{abstract}
Background: Expression of matrix metalloproteinases (MMPs) is up-regulated in human cancers. The aim of present study was to investigate the role of MMP-9 C-1562T polymorphism and its interaction with MMP2 C-735T polymorphism in susceptibility to breast cancer in a population from Western Iran with Kurdish ethnic background. Materials and Methods: The study sample of 205 individuals consisted of 101 breast cancer patients and 104 healthy subjects. MMP-9 C-1562T and MMP-2 C-735T variants were identified using the polymerase chain reaction-restriction fragment length polymorphism (PCR-RFLP) method. Results: Among 67.4\% of studied patients the breast cancer developed in the third and forth decades of the life. The frequency of MMP-9 $\mathrm{T}$ allele was $17.3 \%$ in patients and $10.1 \%$ in controls. The presence of $\mathrm{T}$ allele significantly increased the risk of breast cancer by 1.87 -fold $[\mathrm{OR}=1.87(95 \% \mathrm{CI} 1.05-3.33, \mathrm{p}=0.035)]$. The frequency of MMP-9 CT+TT genotype tended to be higher in those patients with a family history of cancer in first degree-relatives $(\mathbf{3 6 . 8 \%})$ than those without a family history $(28.3 \%, \mathrm{p}=\mathbf{0 . 3 7})$. We observed an interaction between the MMP-9 $-1562 \mathrm{~T}$ allele with MMP-2 -735 C allele that significantly increased the risk of breast cancer [OR=1.42 $(95 \% \mathrm{CI}$ 1.02$1.98, \mathrm{p}=0.036)]$. Conclusions: The present study demonstrated that MMP-9 C-1562T polymorphism alone and in combination with MMP-2 C-735T polymorphism increased the risk of breast cancer that might be a useful biomarker in identifying women at risk of developing breast cancer. Also, this study revealed that in most women from Western Iran breast cancer presents in third and fourth decades of life.
\end{abstract}

Keywords: Breast cancer - MMP-9 C-1562T - MMP-2 C-735T - polymorphism - early-onset

Asian Pac J Cancer Prev, 16 (3), 1175-1179

\section{Introduction}

Breast cancer as the most common cancer among women worldwide comprises $16 \%$ of all female cancers. Breast cancer is the leading cause of mortality among women worldwide. Hereditary, environmental and life style risk factors are involved in the risk of breast cancer (Zhou et al., 2011; Kaviani et al., 2013).

The incidence of breast cancer is increasing in developing countries in a rate of 3-4\% (Babu et al., 2011). Breast cancer is the most prevalent cancer among Iranian women with a crude incidence rate of $24.4 \%$ and agestandardized incidence rate (ASR) of 17.1 per 100000 of all malignancies (Kolahdoozan et al., 2010). Among Asian patients including Iran breast cancer is developed around one decade earlier than that in Caucasians (Kim et al., 2013). In Iran breast cancer predominantly affect younger women in their fourth decade of the life with more aggressive course and poorer prognosis (Babu et al., 2011). Early detection of breast cancer reduces the mortality rates and improves patient prognosis. Also, early-onset and aggressive estrogen receptor (ER) negative breast cancers are common among Iranian women. Lifestyle could be one of the reasons for high prevalence of breast cancer (Babu et al., 2011).

Matrix metalloproteinases (MMPs) are a family of structurally related, zinc-dependent enzymes that play a crucial role in restructuring the extracellular matrix (ECM) (Rahimi et al., 2013). The MMPs substrates are extracellular proteins such as collagen type I-VIII, gelatin, elastin, laminin and also myelin basic protein and several growth factors (Ke et al., 2013). These enzymes increase the cancer cell growth, differentiation, apoptosis, migration, invasion and angiogenesis. In human cancers the MMPs expression are up-regulated. MMP-9 due to type IV collagenolytic activity which disrupts the basement membrane plays an important role in the distant metastatic potential of cancer cells (Przybylowska et al., 2006).

Functional polymorphism of C-1562T (rs3918242) in the promoter of MMP-9 is associated with increased MMP-9 levels (Rahimi et al., 2014). In the presence of MMP-9 $\mathrm{T}$ allele the activity of promoter is 1.5-fold compared to the presence of MMP-9 C allele (Decock et al., 2008).

The influence of MMP-9 C-1562T variants in the risk

${ }^{I}$ Medical Biology Research Center, ${ }^{2}$ Department of Biochemistry, Medical School, Kermanshah University of Medical Sciences, Kermanshah,Iran*For correspondence: zrahimi@kums.ac.ir,rahimizus@yahoo.com 
of breast cancer, its prognosis and metastasis has been investigated in various populations with controversial results (Grieu et al., 2004; Przybylowska et al., 2006; Hughes et al., 2007; Lei et al., 2007; McColgan et al., 2009; Beeghly-Fadiel et al., 2011; Zhou et al., 2011; Slattery et al., 2013; Chiranjeevi et al., 2014).

The MMP-2 gene locates on chromosome 16 at q13-21 and has thirteen exons (Saeed et al., 2013). MMP-2, also known as gelatinase A or 72-kDa type IV collagenase, is secreted from macrophages in fibrous caps and is involved in the remodeling processes (Bahrehmand et al., 2012). $\mathrm{A} \mathrm{C} \rightarrow \mathrm{T}$ transition at nucleotide -735 (rs2285053) in the promoter region of MMP-2 disrupts a SP1 binding element results in lower promoter activity and reducing the MMP-2 expression (Wang et al., 2011).

Previously, we indicated that the C allele of MMP-2 C-735T polymorphism increased the risk of breast cancer by 1.64 -fold (Yari et al., 2014).

The aim of present study was to examine the influence of MMP-9 C-1562T polymorphism and its interaction with MMP-2 C-735T polymorphism in the risk of breast cancer in a population with Kurdish ethnic background from Western Iran.

\section{Materials and Methods}

Sample consisted of 101 patients (100 females and 1 male) with breast cancer and 104 healthy individuals consisted of 103 females and 1 male. The mean age of patients was $49.5 \pm 10.2$ years and the mean age of controls was $40.1 \pm 9$ years.

Diagnosis of breast cancer was according to standard clinical, radiological and histological parameters. Patients and controls had the Kurdish ethnic background and were from provinces of Kermanshah and Ilam from Western Iran. Patients were individuals who admitted to the Kermanshah University of Medical Sciences clinics. Demographic, histopathology and medical characteristics of patients including age, sex, family history of cancer, tumor stage, lymph node metastasis and the status of $\mathrm{ER}$, progesterone receptor (PR) and human epidermal growth factor receptor (HER2) and P53 were obtained from the files of patients. Informed written consent was obtained from each individual before participation in the study. The study was approved by the Ethics Committee of Kermanshah University of Medical Sciences and was in accordance with the principles of the Declaration of Helsinki II.

\section{Genotyping}

From each subject $5 \mathrm{ml}$ EDTA treated whole blood was obtained. Genomic DNA was extracted from peripheral blood leukocytes according to standard phenol-chloroform method as previously described (Rahimi et al., 2006).

The variants of MMP-9 promoter polymorphism at position -1562 were identified by polymerase chain reaction-restriction fragment length polymorphism (PCRRFLP). The PCR included the forward primer of 5 ' GCC TGG CACATA GTA GGC CC--3', and the reverse primer of 5'- CTT CCT AGC CAG CCG GCA TC -3'. The PCR products were digested with $2 \mathrm{U}$ of Sph I restriction enzyme. The presence of MMP-9 T allele produces 247and 188-bp fragments while the MMP-9 C allele results in undigested fragment of 435-bp (Rahimi et al., 2013).

The MMP-2 C-735T polymorphism was detected using PCR-RFLP method. The obtained 300-bp PCR product was digested with Hinf I restriction enzyme. The PCR product remained intact while the $\mathrm{C}$ allele was present but in the presence of $\mathrm{T}$ allele two fragments with 254- and 46-bp were produced (Yari et al., 2014).

\section{Statistics}

The allelic frequencies were calculated by the chromosome counting method. The significance of the difference of alleles and genotype frequencies between the groups was tested using the chi-square method. Data on quantitative characteristics were expressed as means \pm standard deviations. Odds ratios (OR) were calculated as estimates of relative risk for disease and $95 \%$ confidence intervals were measured by logistic regression using SPSS software. Statistical significance was assumed at the $\mathrm{p}<0.05$ level. All of the statistical analyses were performed using SPSS statistical software package version 16.0.

\section{Results}

Demographic and clinical characteristics of breast cancer patients and healthy individuals are demonstrated in Table 1. As indicated in Table 1 there was 40 (39.6\%) patients with a family history of breast cancer in firstdegree relatives. Around $99 \%$ of patients had invasive

Table 1. Characteristics of Patients and $C$ ontrols

\begin{tabular}{|c|c|c|}
\hline Variable & $\begin{array}{c}\text { Patients, } \mathrm{n}=101 \\
\mathrm{n}(\%)\end{array}$ & $\begin{array}{c}\text { Controls, } \mathrm{n}=104 \\
\mathrm{n}(\%)\end{array}$ \\
\hline \multicolumn{3}{|l|}{ Gender } \\
\hline Female & $100(99)$ & 103 (99) \\
\hline Male & $1(1 \%)$ & $1(1 \%), p=0.98$ \\
\hline Age (years) & $\begin{array}{c}49.5 \pm 10.2 \\
\text { (range: } 29-79 \text { ) }\end{array}$ & $\begin{array}{c}40.1 \pm 9 \\
\text { (range: } 28-70), \\
p<0.001\end{array}$ \\
\hline \multicolumn{3}{|l|}{ Family history of cancer } \\
\hline No & $61(60.4)$ & \\
\hline Yes (first-degree relatives) & $40(39.6)$ & - \\
\hline \multicolumn{3}{|l|}{ Tumor size (mm) } \\
\hline Mean (range) & $32(4-90)$ & \\
\hline \multicolumn{3}{|l|}{ Stage } \\
\hline I & $18(24)$ & \\
\hline II & $45(60)$ & - \\
\hline III & $11(14.7)$ & \\
\hline IV & $1(1.3)$ & \\
\hline \multicolumn{3}{|l|}{ Lymph node metastasis } \\
\hline No & $23(29.1)$ & \\
\hline Yes & $56(70.9)$ & - \\
\hline \multicolumn{3}{|l|}{ Histological types } \\
\hline In situ & $1(1.1)$ & \\
\hline Invasive ductal carcinoma & $82(90.1)$ & - \\
\hline Invasive lobular carcinoma & $8(8.8 \%)$ & \\
\hline \multicolumn{3}{|l|}{ ER } \\
\hline Negative & $27(28.4)$ & - \\
\hline Positive & $68(71.6)$ & \\
\hline \multicolumn{3}{|l|}{ PR } \\
\hline Negative & $26(27.4)$ & - \\
\hline Positive & $69(72.6)$ & \\
\hline
\end{tabular}


Table 2. Frequencies of MMP-9 C-1562T Genotypes and Alleles in Patients and Controls

\begin{tabular}{llcccc}
\hline $\begin{array}{l}\text { Genotype } \\
\text { MMP-9 C-1562T }\end{array}$ & \multicolumn{2}{c}{$\begin{array}{c}\text { Patients } \mathrm{n}=101 \\
\mathrm{n}(\%)\end{array}$} & $\begin{array}{c}\text { Controls } \mathrm{n}=104 \\
\mathrm{n}(\%)\end{array}$ & OR $(95 \% \mathrm{CI}, \mathrm{p})$ \\
\hline Co dominant & $\mathrm{CC}$ & $68(67.3)$ & $84(80.8)$ & \\
& $\mathrm{CT}$ & $31(30.7)$ & $19(18.3)$ & $4.49, \mathrm{p}=0.034$ & $2.015(1.05-3.88, \mathrm{p}=0.036)$ \\
& $\mathrm{TT}$ & $2(2)$ & $1(1)$ & $0.57, \mathrm{p}=0.45$ & $1.57(0.46-5.28, \mathrm{p}=0.46)$ \\
Dominant & $\mathrm{CC}$ & $68(67.3)$ & $84(80.8)$ & & \\
& $\mathrm{CT}+\mathrm{TT}$ & $33(32.7)$ & $20(19.2)$ & $4.83, \mathrm{p}=0.028$ & $2.04(1.07-3.87, \mathrm{p}=0.029)$ \\
Recessive & $\mathrm{CT}+\mathrm{CC}$ & $99(98)$ & $103(99)$ & & \\
\multirow{2}{*}{ Over dominant } & $\mathrm{TT}$ & $2(2)$ & $1(1)$ & $0.36, \mathrm{p}=0.54$ & $2.08(0.18-23.31, \mathrm{p}=0.55)$ \\
\multirow{4}{*}{ Allele frequency } & $\mathrm{CC}+\mathrm{TT}$ & $70(69.3)$ & $85(81.7)$ & & \\
& $\mathrm{CT}$ & $31(30.7)$ & $19(18.3)$ & $4.28, \mathrm{p}=0.038$ & $1.98(1.03-3.81, \mathrm{p}=0.04)$ \\
& $\mathrm{C}$ & $167(82.7)$ & $187(89.9)$ & & \\
& $\mathrm{T}$ & $35(17.3)$ & $21(10.1)$ & $4.54, \mathrm{p}=0.033$ & $1.87(1.05-3.33, \mathrm{p}=0.035)$ \\
\hline
\end{tabular}

Table 3. Carrier Odds Ratios Interaction between Mmp-9 T with Mmp-2 C Alleles in Breast Cancer Patients

\begin{tabular}{cccc}
\hline $\begin{array}{c}\text { Control group } \\
\mathrm{n}(\%)\end{array}$ & $\begin{array}{c}\text { Patients } \\
\mathrm{n}(\%)\end{array}$ & $\begin{array}{c}\text { MMP-2 } \\
\mathrm{C}\end{array}$ & $\begin{array}{c}\text { MMP-9 } \\
\mathrm{T}\end{array}$ \\
\hline [OR $(95 \% \mathrm{CI}, \mathrm{p})]$ & & - \\
\hline $\begin{array}{c}\text { Reference group } \\
120(75.9)\end{array}$ & $\begin{array}{c}\text { Reference group } \\
\text { (13.9) }\end{array}$ & - & - \\
$6(3.8)$ & $140(74.5)$ & + & - \\
$10(6.3)$ & $21(11.2)$ & - & + \\
& {$[1.42(1.02-1.98, \mathrm{p}=0.036)]$} & + & + \\
\hline
\end{tabular}

ductal and lobular carcinoma. Approximately $72 \%$ of patients were estrogen and progesterone receptor positive (Table 1).

There were $10(10.2 \%)$ and $28(28.6 \%)$ patients aged below 30 and 40 years, respectively. The highest incidence of breast cancer existed in women aged 40-49 years (38.8\%) followed in order of frequency among women aged 30-39 (28.6\%), 50-59 (12.2\%), 20-29 (10.2\%), 60-69 $(8.2 \%)$ and $70-79$ years $(2 \%)$.

Agarose gel electrophoresis pattern of some of RFLP

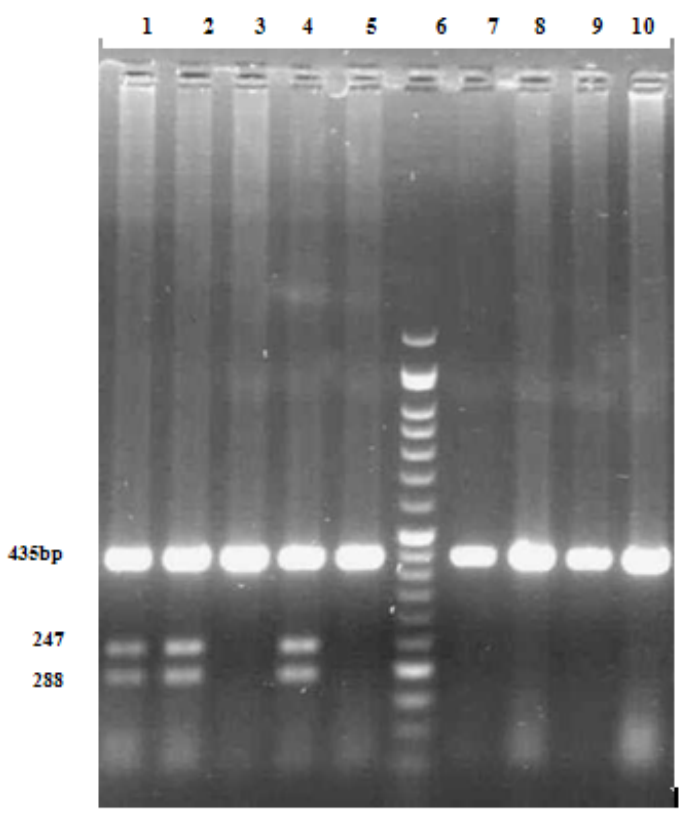

Figure 1.Agarose Gel Electrophoresis Pattern of Some RFLP Products of the MMP-9 C-1562T Polymorphism products of the MMP-9 C-1562T polymorphism is demonstrated in Figure 1.

Distribution of MMP-9 genotypes was in hardyWeinberg equilibrium in both patients and controls $\left(\chi^{2}=0.51, \chi^{2}=0\right.$, respectively, $\left.\mathrm{p}>0.1\right)$.

The frequencies of MMP-9 C-1562T genotypes and alleles are presented in Table 2. In co-dominant model the frequency of MMP-9 CT genotype in patients was significantly higher $(30.7 \%, \mathrm{p}=0.034)$ than that in controls $(18.3 \%)$ and increased the susceptibility to breast cancer by 2.015 -fold $(\mathrm{p}=0.036)$. In dominant model the combined genotype of $\mathrm{CT}+\mathrm{TT}$ increased the risk of breast cancer by 2.04 times $(p=0.029)$. In over dominant model the presence of CT genotype was associated with 1.98-fold increased risk of breast cancer $(\mathrm{p}=0.04)$. The frequency of MMP-9 T allele was $17.3 \%$ in patients and $10.1 \%$ in controls, respectively and the presence of this mutant allele significantly increased the risk of breast cancer by 1.87 tim es $[\mathrm{OR}=1.87(95 \% \mathrm{CI} 1.05-3.33, \mathrm{p}=0.035)]$.

The frequency of MMP-9 CT+TT genotype tended to be higher in those patients with a family history of cancer in first degree-relatives [CT+TT, $n=14(36.8 \%), C C, n=24$ $(63.2 \%)]$ than those without a family history of cancer [CT+TT, $n=17(28.3 \%), \mathrm{CC}, \mathrm{n}=43(71.7 \%), \mathrm{p}=0.37)]$.

Examining the synergistic effects of both polymorphisms revealed in the presence of both MMP-9 $\mathrm{T}$ and MMP-2 $\mathrm{C}$ alleles the risk of breast cancer increased 1.42 times $[\mathrm{OR}=1.42,95 \% \mathrm{CI} 1.02-1.98, \mathrm{p}=0.036]$ (Table $3)$.

\section{Discussion}

The present study detected a significant association between MMP-9 C-1562T polymorphism and the risk of breast cancer. We indicated that the presence of MMP-9 T allele increased susceptibility to breast cancer by 1.87 fold. Also, there was a synergism between MMP-9T and MMP-2 $\mathrm{C}$ alleles to increase the risk of breast cancer by 1.42 times. However, the MMP-9 variants were not associated with the lymph node metastasis and steroid hormone receptor status in our studied population.

MMPs play a role in tumor initiation and growth, stimulation of angiogenesis, activation of growth factors and receptors, apoptosis and metastasis of tumors (Chiranjeevi et al., 2014).

MMP-9 that is also known as gelatinase B or type IV 
collagenases is a proteolytic enzyme that degrades type IV collagen, a major component of the basement membrane. It has been demonstrated that the presence of MMP-9 -C1562T abolishes the binding of transcription repressor protein, resulting in a higher activity of the MMP-9 T allele (Przybylowska et al., 2006). So, the MMP-9 C-1562T polymorphism might increase degradation of ECM with lymph node metastasis. A positive correlation between expression levels and genotypes of the MMP-9T allele and a higher risk of advanced breast cancer has been indicated due to the higher promoter expression in the presence of this allele. Association of higher plasma MMP-9 levels with poor prognosis in breast cancer patients has been reported (Chiranjeevi et al., 2014).

There are controversial reports related to the role of MMP-9 C-1562T variants in susceptibility to breast cancer or influence on its prognosis. Some studies showed an evidence of association between MMP-9 C-1562T polymorphism with cancer susceptibility. In a study from Sweden a moderate increased risk of developing breast cancer was observed in the presence of TT genotype (Lei et al., 2007). Also, in a study among Indians an association between the TT genotype with the risk of breast cancer was detected (Chiranjeevi et al., 2014). However, other studies did not detect such association. Among Chinese breast cancer patients from Shanghai Breast Cancer Genetics Study, the MMP-9 C-1562T polymorphism was not associated with the risk of cancer (Beeghly-Fadiel et al., 2011). In a meta-analysis conducted by McColgan and Sharma in 2009, MMP-9 C-1562T was not associated with the risk of breast cancer (McColgan et al., 2009). Subsequent meta-analysis confirmed an absence of association between the risk of breast cancer and MMP-9 C-1562T (Zhou et al., 2011).

An evidence of association between MMP-9 C-1562T genotypes and clinical outcome of the cancer has been provided in some studies. Among mixed ethnicity Caucasians with breast cancer the presence of MMP-9 CT genotypes significantly increased the risk of lymph node metastasis (Hughes et al., 2007). Over expression of MMP-9 due to promoter polymorphism and elevation of MMP-9 level may increase migration of tumor cell and progression of cancer through degradation of ECM. Also, variable individual susceptibility to breast cancer and its outcome might be explained by influence of MMPs variants on tumor microenvironment (Hughes et al., 2007).

In a study from Poland the MMP-9 $\mathrm{T}$ allele was associated with poor differentiation, tumor size and steroid hormone receptor status but not with lymph node involvement (Przybylowska et al., 2006). Also, among breast cancer patients the presence of MMP-9 -1562 T allele was associated with good prognosis in these patients (Grieu et al., 2004). Further, in a study of mixed population of Hispanic and non-Hispanic white women both MMP3 (rs650108) and MMP9 (rs3918261) were associated with ER-/PR- tumors (Slattery et al., 2013). However, among Swedish patients this polymorphism did not affect the prognosis. Also, no association was detected between this polymorphism and tumor size, steroid hormone receptor status, lymph node metastasis or differentiation (Lei et al., 2007). Among Indians the stratification of MMP-9 genotypes based on the histological classification status did not indicate a difference (Chiranjeevi et al., 2014).

Controversial reports related to the role of MMP-9 $\mathrm{C}-1562 \mathrm{~T}$ in susceptibility to breast cancer and its clinical outcome could be due to differences in ethnicity, sample size, subtypes of cancer, environmental factors and genegene interactions.

In our previous report the MMP-2 -735 C allele was found to be a risk factor for breast cancer (Yari et al., 2014). In the present study the increased risk of breast cancer in the concomitant presence of both MMP-9 -1562 $\mathrm{T}$ and MMP-2 -735 C allele could be attributed to higher promoter activity and expression of promoter of both genes in the presence of these alleles with consequence of increased breast cancer risk (Beeghly-Fadiel et al., 2011; Wang et al., 2011; Saedi et al., 2012; Yari et al., 2014).

In contrast to developed countries (Kim et al., 2013) in the present study around $67.4 \%$ of the patients developed breast cancer in the third and forth decades of their life. The presence of early-onset breast cancer with higher mortality and morbidity should be considered in screening and prevention programs of the cancer of the country.

In conclusion, the present study demonstrates the MMP-9 C-1562T polymorphism increases the risk of breast cancer and also, synergistically acts with MMP-2 C-735T polymorphism to increase the risk of breast cancer that might be a useful biomarker in identifying women at risk of developing breast cancer. Also, this study indicates that in women from Western Iran breast cancer present mostly in third and fourth decades of life.

\section{Acknowledgements}

This work was financially supported by a grant from Vice Chancellor for Research of Kermanshah University of Medical Sciences, Kermanshah, Iran.

\section{References}

Babu GR, Samari G, Cohen SP, et al (2011) Breast cancer screening among females in Iran and recommendations for improved practice: a review. Asian Pac J Cancer Prev, 12, 1647-55.

Bahrehmand F, Vaisi-Raygani A, Kiani A, et al (2012) Matrix metalloproteinase-2 functional promoter polymorphism G1575A is associated with elevated circulatory MMP-2 level and increased risk of cardiovascular disease in systemic lupus erythematosus patients. Lupus, 21, 616-24.

Beeghly-Fadiel A, Lu W, Shu XO, et al (2011) MMP9 polymorphisms and breast cancer risk: a report from the shanghai breast cancer genetics study. Breast Cancer Res Treat, 126, 507-13.

Chiranjeevi P, Mrudula Spurthi K, Santhoshi Rani N, et al (2014) Gelatinase B (-1562C/T) polymorphism in tumor progression and invasion of breast cancer. Tumor Biol, 35, 1351-6.

Decock J, Paridaens R, Ye S (2008) Genetic polymorphisms of matrix metalloproteinases in lung, breast and colorectal cancer. Clin Genet, 73, 197-211.

Grieu F, Li WQ, Iacopetta B (2004) Genetic polymorphisms in the MMP-2 and MMP-9 genes and breast cancer phenotype. Breast Cancer Res Treat, 88, 197-204.

Hughes S, Agbaje O, Bowen RL, et al (2007) Matrix 
metalloproteinase single-nucleotide polymorphisms and haplotypes predict breast cancer progression. Clin Cancer Res, 13, 6673-80.

Kaviani A, Neishaboury MR, Mohammadzadeh N, AnsariDamavandi M, Jamei K (2013) Effects of obesity on presentation of breast cancer, lymph node metastasis and patient survival: A retrospective review. Asian Pac J Cancer Prev, 15, 2225-9.

Ke P, Wu Z-D, Wen H-S, et al (2013) Current evidence on associations between the MMP-7 (-181A $>\mathrm{G})$ polymorphism and digestive system cancer risk. Asian Pac J Cancer Prev, 14, 2269-72.

Kim H, Choi DH (2013) Distribution of BRCA1 and BRCA2 mutations in Asian patients with breast cancer. J Breast Cancer, 16, 357-65.

Kolahdoozan S, Sajadi A, Radmard AR, Khademi H (2010) Five common cancers in Iran. Arch Iran Med, 13, 143-6.

Lei H, Hemminki K, Altieri A, et al (2007). Promoter polymorphisms in matrix metalloproteinases and their inhibitors: few associations with breast cancer susceptibility and progression. Breast Cancer Res Treat, 103, 61-9.

McColgan P, Sharma P (2009). Polymorphisms of matrix metalloproteinases 1, 2, 3 and 9 and susceptibility to lung, breast and colorectal cancer in over 30,000 subjects. Int $J$ Cancer, 125, 1473-8.

Przybylowska K, Kluczna A, Zadrozny M, et al (2006) .Polymorphisms of the promoter regions of matrix metalloproteinases genes MMP-1 and MMP-9 in breast cancer. Breast Cancer Res Treat, 95, 65-72.

Rahimi Z, Merat A, Gerard N, Krishnamoorthy R, Nagel RL (2006). Implications of the genetic epidemiology of globin haplotypes linked to the sickle gene in Southern Iran. Hum Biol, 78, 719-31.

Rahimi Z, Rahimi Z, Omidi Shahsavandi M, Bidoki K, Rezaei M (2013) Matrix metalloproteinase 9 (-1562 C:T) polymorphism as a biomarker of susceptibility to severe preeclampsia. Biomark Med, 7, 93-8.

Rahimi Z, Rahimi Z, Aghaei A, Vaisi-Raygani A (2014). AT2R -1332 G:A polymorphism and its interaction with AT1R 1166 A:C, ACE I/D and MMP-9 -1562 C:T polymorphisms: Risk factors for susceptibility to preeclampsia.Gene, 538, 176-81.

Saedi M, Vaisi-Raygani A, Khaghani S, et al (2012). Matrix metalloproteinas-9 functional promoter polymorphism $1562 \mathrm{C}>\mathrm{T}$ increased risk of early-onset coronary artery disease. Mol Biol Rep, 39, 555-62.

Saeed HM, Alanazi MS, Parine NR, et al (2013). Matrix metalloproteinase-2 (-1306 c>t) promoter polymorphism and risk of colorectal cancer in the Saudi population. Asian Pac J Cancer Prev, 14, 6025-30.

Slattery ML, John E, Torres-Mejia G, et al (2013). Matrix metalloproteinase genes are associated with breast cancer risk and survival: the breast cancer health disparities study. PLOS ONE, 8, 63165.

Wang F, Jin X-p, Zhu M, et al (2011). Genotype association of C (-735) T polymorphism of the MMP-2 gene with the risk of carotid atherosclerosis-vulnerable plaque in the Han Chinese population. Vasc Med, 16, 13-18.

Yari K, Rahimi Z, Moradi MT, Rahimi Z (2014). The MMP-2$735 \mathrm{C}$ allele is a risk factor for susceptibility to breast cancer. Asian Pac J Cancer Prev, 15, 6199-203.

Zhou P, Du LF, Lv GQ, et al (2011). Current evidence on the relationship between four polymorphisms in the matrix metalloproteinases (MMP) gene and breast cancer risk: a meta-analysis. Breast Cancer Res Treat, 127, 813-8. 